\title{
PERAN PETUGAS KESEHATAN TERHADAP SANITASI RUMAH DI KELURAHAN SEMANGGI KOTA SURAKARTA
}

\author{
Windi Wulandari ${ }^{1}$, Dewi Anjar Kartikasari ${ }^{2}$, Lufiana Puspita Ratri ${ }^{3}$ \\ ${ }^{1}$ Program Studi Kesehatan Masyarakat, Fakultas Ilmu Kesehatan Universitas \\ Muhammadiyah Surakarta Jl. A. Yani Tromol Pos I Pabelan Kartasura Surakarta \\ Email: ${ }^{1}$ windi.wulandari@ums.ac.id ${ }^{2}$ dewianjarkartika16@gmail.com \\ ${ }^{3}$ puspitaratri121@gmail.com
}

\begin{abstract}
ABSTRAK
Kondisi sanitasi rumah yang tidak memenuhi syarat kesehatan dapat menimbulkan berbagai macam penyakit dan gangguan kesehatan. Data pemeriksaan rumah sehat di Kelurahan Semanggi diperoleh sebanyak 43,25\%. Peran petugas sanitasi dan kepala puskesmas menjadi salah satu yang menentukan keberhasilan cakupan dalam pelaksanaan inspeksi sanitasi di wilayah puskesmas selama 1 (satu) tahun. Berdasarkan survei pendahuluan yang telah dilakukan menunjukkan bahwa masyarakat di kelurahan semanggi jarang mendapatkan info maupun penyuluhan dari petugas yang berkaitan dengan rumah sehat. Penelitian ini bertujuan untuk menganalisis peran petugas terhadap sanitasi rumah di Desa Semanggi Kota Surakarta. Jenis penelitian ini adalah survei analitik dengan menggunakan desain penelitian cross-sectional. Populasi penelitian ini adalah masyarakat yang bertempat tinggal di Kelurahan Semanggi dengan populasi 4.772 rumah dan jumlah sampel 108 rumah, dengan teknik pengambilan proportionate random sampling. Hasil penelitian menunjukkan ada hubungan antara peran petugas kesehatan dengan sanitasi rumah $(\mathrm{p}=0,000)$. Petugas kesehatan mempunyai peranan dalam terwujudnya rumah sehat di kelurahan semanggi.
\end{abstract}

Kata kunci: sanitasi rumah, peran petugas kesehatan

\begin{abstract}
House Sanitation condition that does not meet health requirements can cause various kinds of diseases and health problems. Data on examination of healthy house in Semanggi sub-district was $43.25 \%$. Sanitation officers and puskesmas heads help the success the implementation of house sanitation and inspections in the area annually. The preliminary survey showed that the people in the Semanggi village rarely received information or counseling from sanitation officers related to healthy houses. This study aims to analyze the role of sanitation officers in home sanitation in Semanggi Village, Surakarta City. This type of research used analytical survey using a cross-sectional research design. The population of this study were
\end{abstract}


people who lived in Semanggi Village with a population of 4,772 houses and a total sample of 108 houses, with the taking technique of proportionate random sampling. The results showed that there was a relationship between the role of officers and home sanitation $(\mathrm{p}=$ $0,000)$. Health workers have a role in the realization of healthy homes in the semanggi village.

Keywords: home sanitation, the role of health workers

\section{PENDAHULUAN}

Kesehatan merupakan salah satu hak asasi manusia dan investasi untuk keberhasilan pembangunan bangsa, maka perlu diselenggarakan pembangunan kesehatan secara menyeluruh dan berkesinambungan. Tujuan pembangunan kesehatan menuju Indonesia Sehat (2015-2025) adalah meningkatkan kemauan, kesadaran dan kemampuan hidup bagi setiap manusia agar terwujud derajat kesehatan masyarakat yang optimal.

Salah satu indikator untuk meningkatkan derajat kesehatan yang optimal adalah dengan terwujudnya rumah sehat pada setiap masyarakat. Rumah merupakan salah satu kebutuhan dasar manusia yang berfungsi sebagai tempat tinggal atau hunian dan sarana pembinaan keluarga. Rumah harus sehat dan nyaman agar penghuninya dapat melakukan aktivitas sehari-hari dengan aman tanpa adanya resiko/gangguan. Rumah sehat merupakan salah satu impian bagi semua orang. Rumah tidak hanya sekedar sebagai tempat berlindung dari hujan dan terik matahari, tetapi juga menjadi simbol status sosial dan sumber inspirasi bagi pemilik.

Kondisi sanitasi rumah yang tidak memenuhi syarat kesehatan dapat menimbulkan berbagai macam penyakit dan gangguan kesehatan diantaranya penyakit pada saluran pernafasan, penyakit kulit, penyakit akibat binatang pengganggu atau vektor penyakit, menyebabkan kecelakaan serta menyebabkan masalah kesehatan lingkungan. Di Indonesia masalah yang berhubungan dengan kesehatan lingkungan perumahan meliputi rumah tangga dengan akses air minum layak sebanyak $(71,14 \%)$, rumah tangga kumuh sebanyak $(6,07 \%)$, rumah tangga yang memiliki akses terhadap sanitasi layak sebesar $(67,80 \%)$ (Profil Kesehatan Indonesia 2016).

Data dari puskesmas sangkrah bahwa presentase rumah sehat terendah berada di kelurahan semanggi. Data pemeriksaan rumah sehat di kelurahan semanggi diperoleh angka 43,25\%, dengan jumlah rumah sebanyak 4.772 yang terdiri dari 23 RW. Kondisi perumahan di kelurahan tersebut cenderung sangat padat dengan jarak yang sangat berdekatan, keadaan sanitasi yang buruk ditandai dengan kondisi lingkungan yang kumuh serta adanya selokan didepan rumah yang bau serta terbuka. Selain itu kelurahan tersebut dekat dengan sungai serta jalur perlintasan kereta api. Kondisi sanitasi rumah yang buruk dapat disebabkan oleh berbagai faktor, salah satunya yaitu Peran Petugas.

Petugas kesehatan tentunya berpengaruh dalam terwujudnya rumah 
sehat. Bagi masyarakat yang tidak mengetahuai mengenai sanitasi rumah sehat tentunya akan sangat mebutuhkan informasi untuk menambah wawasan dan ilmu bagi masyarakat setempat. Peran petugas seperti pemberian informasi melalui penyuluhan dan pengecekan rumah setiap masyarakat tentunya sangat dibutuhkan. Hal tersebut haruslah dilakukan secara rutin oleh petugas untuk menjaga agar rumah masyarakat tetap menjadi rumah sehat. Jika sanitasi rumah sehat baim maka penguhuni rumah tersebut akan merasa nyaman dan terhindar dari binatang penganggu yang dapat meyebabkan timbulnya dan penularan penyakit.

\section{METODE PENELITIAN}

Jenis penelitian yang digunakan adalah Kuantitatif analitik dengan menggunakan desain penelitian crosssectional. Populasi penelitian ini adalah masyarakat di kelurahan Semanggi dengan jumlah populasi keseluruhan 4.772 rumah. Besar sampel dalam penelitian ini adalah sebanyak 108 rumah dengan responden ibu rumah tangga di Kelurahan Semanggi Kecamatan pasar Kliwon Surakarta dengan tehnik pengambilan sampel Proportionate Random Sampling.

Tehnik pengumpulan data dilakukan dengan wawancara dan observasi menggunakan lembar observasi persyaratan rumah sehat dan lembar kuesioner. Analisis data dalam penelitian ini terdiri dari analisis univariat dan bivariat. Uji statistik yang digunakan untuk melihat hubungan kedua variabel menggunakan uji chi square dalam batas kepercayaan $(\alpha=0,05)$.

\section{HASIL DAN PEMBAHASAN}

\section{Karakteristis Responden}

Pada penelitian ini karakteristik responden yang dianalisis yaitu usia dan pekerjaan ibu. Berikut adalah Tabel karakterisistik responden :

Tabel 1. Distribusi Frekuensi Karakteristik Responden

\begin{tabular}{|c|c|c|c|}
\hline $\begin{array}{c}\text { Karakteris- } \\
\text { tik } \\
\text { Responden }\end{array}$ & $\begin{array}{c}\text { Frekuensi } \\
\text { (N) }\end{array}$ & $\begin{array}{c}\text { Persentase } \\
(\%)\end{array}$ & $\begin{array}{c}\text { Mean } \\
\text { SD }\end{array}$ \\
\hline \multicolumn{4}{|c|}{ Usia } \\
\hline $\begin{array}{c}\text { Remaja } \\
(\leq 25 \text { tahun })\end{array}$ & 5 & 4,6 & \\
\hline $\begin{array}{c}\text { Dewasa } \\
\text { (26-45 tahun) }\end{array}$ & 47 & 43,5 & $\begin{array}{c}2,71 \pm \\
0,587\end{array}$ \\
\hline $\begin{array}{c}\text { Lansia } \\
(\geq 46 \text { tahun })\end{array}$ & 56 & 51,9 & \\
\hline Total & 108 & 100 & \\
\hline \multicolumn{4}{|c|}{ Pekerjaan } \\
\hline IRT & 52 & 48,1 & \multirow{6}{*}{$\begin{array}{c}2,32 \pm \\
1,576\end{array}$} \\
\hline Swasta & 16 & 14,8 & \\
\hline Wiraswasta & 15 & 13,9 & \\
\hline Pelajar/Mhs & 3 & 2,8 & \\
\hline Pedagang & 22 & 20,4 & \\
\hline Total & 108 & 100 & \\
\hline
\end{tabular}

Berdasarkan Tabel 1 diketahui bahwa distribusi usia responden paling banyak yaitu usia lansia $\geq 46$ tahun sebanyak 56 responden dengan presentase $51,9 \%$. Jenis pekerjaan responden di kelurahan semanggi paling banyak yaitu bekerja sebagai ibu rumah tangga (IRT) berjumlah 52 responden dengan presentase $48,1 \%$.

\section{Peran Petugas Kesehatan dan Sanitasi Rumah \\ Sesuai dengan Permenkes RI No 13 Tahun 2015 tentang} Penyelenggaraan Pelayanan Kesehatan Lingkungan di Puskesmas, petugas kesehatan lingkungan mempunyai peran untuk memberikan intervensi berupa komunikasi, informasi dan edukasi serta penggerakan/ pemberdayaan masyarakat. Dengan 
adanya peraturan tersebut makan peran petugas kesehatan dalam penelitian ini merupakan pemberian informasi tentang rumah sehat maupun dalam melakukan inspeksi rumah sehat. Keikutsertaan petugas kesehatan dalam mensosialisasi rumah sehat, pentingnya sehat maupun melakukan pemeriksaan rutin sanitasi dan perumahan sehat akan memberikan dorongan positif terhadap keinginan masyarakat untuk dapat memeperoleh atau memiliki rumah sehat.

Pengukuran peran petugas kesehatan dan rumah sehat di ukur dengan menggunakan lembar kuesioner. Berikut adalah tabel analisis:

Tabel 2. Anallisis Univariat Peran Petugas dan Rumah Sehat

\begin{tabular}{ccc}
\hline $\begin{array}{c}\text { Peran } \\
\text { Petugas }\end{array}$ & Frekuensi & $\begin{array}{c}\text { Persentase } \\
(\%)\end{array}$ \\
\hline Tidak & 61 & 56,5 \\
Aktif & & \\
Aktif & 47 & 43.5 \\
Total & 108 & 100 \\
\hline Kondisi & & \\
Rumah & & \\
Tidak & 83 & 76,9 \\
Sehat & & \\
Sehat & 25 & 23,1 \\
Total & 108 & 100 \\
\hline
\end{tabular}

Berdasarkan Tabel 2 diketahui bahwa peran petugas paling banyak yaitu pada kategori peran petugas tidak aktif dengan jumlah 61 responden $(43,5 \%)$. Kategori rumah sehat paling banyak yaitu responden yang memiliki rumah tidak sehat dengan jumlah 83 rumah responden $(76,9 \%)$.

\section{Hubungan Peran Petugas dengan Sanitasi Rumah}

Pengukuran peran petugas sanitarian dengan sanitasi rumah yang telah dilakukan dan dianalisis dengan menggunakan uji chi square dimana diperoleh nilai signifikan $p$ sebesar $(0,000<0,05)$. Hasil tersebut menunjukkan bahwa adanya hubungan yang signifikan antara peran petugas sanitarian dengan sanitasi rumah di Kelurahan Semanggi Kota Surakarta. Hal ini menunjukan bahwa semakin rendah peran petugas sanitarian maka dapat berpengaruh terhadap kondisi sanitasi rumah. Semakin kurangnya informasi dan kunjungan dari peran petugas maka semakin rendah pengetahuan dan perilaku masyarakat terhadap kepemilikan rumah sehat.

Tabel 3. Hubungan Peran Petugas dengan Sanitasi Rumah

\begin{tabular}{|c|c|c|c|c|c|}
\hline \multirow{3}{*}{$\begin{array}{c}\text { Peran } \\
\text { Petugas }\end{array}$} & \multicolumn{4}{|c|}{$\begin{array}{c}\text { Kategori Sanitasi } \\
\text { Rumah Ditinjau Dari } \\
\text { Rumah Sehat }\end{array}$} & \multirow{3}{*}{$\begin{array}{c}p- \\
\text { value }\end{array}$} \\
\hline & \multicolumn{2}{|c|}{$\begin{array}{l}\text { Tidak } \\
\text { Sehat }\end{array}$} & \multicolumn{2}{|c|}{ Sehat } & \\
\hline & $\mathbf{N}$ & $(\%)$ & $\mathbf{N}$ & $(\%)$ & \\
\hline Tidak & 56 & 91,8 & 5 & 8,2 & 0000 \\
\hline Aktif & 27 & 57,4 & 20 & 42,6 & \\
\hline
\end{tabular}

Berdasarkan Tabel 3 diketahui bahwa nilai $\mathrm{p}$ sebesar $(0,000<0,05)$ sehingga Ho ditolak yang artinya ada hubungan antara peran petugas dengan sanitasi rumah di Kelurahan Semanggi kota Surakarta. Pengukuran peran petugas dengan sanitasi rumah pada 108 rumah di Kelurahan Semanggi kota Surakarta kategori peran petugas tidak aktif terdapat 56 responden $(91,8 \%)$ yang memilik rumah tidak sehat serta 5 responden $(8,2 \%)$ yang memiliki rumah sehat. Kategori peran petugas aktif terdapat 27 responden $(57,4 \%)$ memiliki rumah tidak sehat serta 20 responden $(42,6 \%)$ yang memiliki rumah sehat.

Penelitian ini sejalan dengan penelitian yang dilakukan oleh Syifa (2014) menyatakan bahwa ada 
hubungan antara kunjungan petugas sanitarian dengan rumah sehat di Dusun Parung Goong Desa Sukamanah Kecamatan Jambe Kabupaten Tangerang dengan nilai signifikan $\mathrm{p}=$ 0,036 . Penelitian lain yang mendukung yaitu penelitian yang dilakukan oleh bungsu, (2008) menyatakan bahwa ada hubungan antara peran petugas dengan kepemilikan rumah sehat di Kecamatan Peureulak Timur Kabupaten Aceh Timur dengan nilai signifikan $\mathrm{p}=$ 0,013 .

Peran petugas kesehatan adalah suatu kegiatan yang diharapkan dari seorang petugas kesehatan yang memberikan pelayanan kesehatan kepada masyarakat untuk meningkatkan derajat kesehatan masyarakat (setiadi, 2008). Peran petugas kesehatan tidak hanya memberikan informasi saja tetapi pengecekan secara berkala pada sanitasi rumah juga sangat diperlukan. Menurut Depkes (1999), peran petugas sanitasi dan kepala puskesmas sangat menentukan keberhasilan cakupan pelaksanaan inspeksi sanitasi diwilayah puskesmas selama satu tahun.

Peran petugas kesehatan tentunya sangat mempengaruhi dalam terwujudnya rumah sehat. Pada daerah semanggi petugas kesehatan yang memberikan informasi ataupun melakukan pengecekan sanitasi rumah sehat masih kurang, hal tersebut dibuktikan dengan hasil penelitian yang menyatakan bahwa $61 \%$ peran petugas masih belum aktif. Petugas kesehatan yang hadir hanya memberikan penyuluhan mengenai kesehatan salah satunya mengenai demam berdarah. Pengecekan mengenai sanitasi rumah dan penyuluhan mengenai sanitasi rumah belum diadakan, hal itu membuat kondisi rumah masyarakat masih banyak yang belum dapat dikatan rumah sehat. Hal tersebut dibuktikan dengan hasil penelitian yang telah dilakukan menyatakan bahwa sekitar $83 \%$ rumah masyarakat masih belum termasuk rumah sehat. Hal ini sejalan dengan penelitian Bungsu (2008), dimana hasil uji statistik dengan uji chi square $(\mathrm{p}=0,013)$ menunjukkan ada hubungan signifikan antara peran petugas dengan kepemilikan rumah sehat.

\section{KESIMPULAN}

Berdasarkan hasil penelitian yang telah dilakukan terhadap 108 responden di Kelurahan Semanggi Kota Surakarta, dapat di simpulakan bahwa terdapat hubungan antara peran petugas dengan sanitasi rumah dengan nilai $\mathrm{p}=0,000$. Hal ini berarti bahwa petugas kesehatan mempunyai peranan dalam terwujudnya sanitasi rumah di Kelurahan Semanggi.

\section{UCAPAN TERIMAKASIH}

Terimakasih kepada pihak yang telah membantu dalam penelitian ini, sehingga penelitian dapat berjalan dengan lancar. Bagi dinas kesehatan kota surakarta dan puskesmas sangkrah yang telah mengijinkan kami untuk melakukan penelitian dan memberikan data-data yang kami butuhkan. Bagi masyarakat di wilayah semanggi yang telah bersedia menjadi responden dan mengijinkan kami untuk melakukan survei ke rumah-rumah. 


\section{DAFTAR PUSTAKA}

Bungsu, R. (2008). Pengaruh Karakteristik Individu, Pengetahuan, Sikap dan Peran Petugas Terhadap Kepemilikan Rumah Sehat Di Kecamatan Peureulak Timur. Tesis. Universitas Sumatera Utara.

Departemen Kesehatan Republik Indonesia.(1999). Keputusan Menteri Kesehatan Nomor829/Menkes/SK/VII/1999 tentang Persyaratan Kesehatan Perumahan. Jakarta: Depkes RI

Departemen Kesehatan Republik Indonesia. (2015). Peraturan Menteri Kesehatan Republik Indonesia Nomor 13 Tahun 2015 Tentang Penyelenggaraan Pelayanan Kesehatan Lingkungan di Puskesmas. Jakarta: Depkes RI

Departemen Kesehatan Republik Indonesia. (2016). Profil kesehatan Indonesia. Jakarta: Depkes RI

Puskesmas Sangkrah. (2016). Profil Puskesmas Sangkrah Kecamatan Pasar Kliwon Kota Surakarta. Surakarta: Puskesmas Sangkrah

Setiadi, (2008). Konsep dan Perawatan Keluarga. Yogyakarta: Graha Ilmu.

Syifa, W. (2014). Faktor-Faktor yang Berhubungan dengan Rumah Sehat di Dusun Parung Goong Desa Sukamanah Kecamatan Jambe Kabupaten Tangerang. Skripsi. Universitas esa tunggul Jakarta barat. 